\title{
Task load in user interfaces on didactic mobile applications for users with ADHD
}

\section{Carga cognitiva en interfaces de usuario en aplicaciones móviles didácticas para usuarios con TDAH}

\author{
PONCE-MENDOZA, Ulises*广, GARCÍA-GORROSTIETA, Jesus Miguel and MADRID- \\ MONTEVERDE, José David \\ Universidad de la Sierra, División de Ingeniería y Tecnologías, Programa Educativo de Ingeniería en Sistemas \\ Computacionales
}

ID $1^{\text {st }}$ Author: Ulises, Ponce-Mendoza / ORC ID: 0000-0003-0719-7136, CVU CONACYT ID: 94012

ID $1^{\text {st }}$ Coauthor: Jesus Miguel, García-Gorrostieta / ORC ID: 0000-0001-6246-6795

ID $2^{\text {nd }}$ Coauthor: José David, Madrid-Monteverde / ORC ID: 0000-0001-5945-2165

DOI: $10.35429 / J C S I .2020 .17 .6 .1 .6$

Received January 30, 2020; Accepted June 01, 2020

\begin{abstract}
Objectives: Measure the task load using the user interface on didactic mobile applications by children with ADHD using the NASA-TLX instrument. Explore the feasibility of using the NASA-TLX instrument to measure task load in users with different abilities. Methodology: Qualitative sample exploratory study with direct application of a NASA-TLX instrument adapted to users with ADHD who use a didactic mobile app who belong to an age group from 5 to 15 years old population in the CAM \# 8 in Moctezuma, Sonora. The instrument is applied indirectly, assisted by the educator in order to interpret the subjects' responses. Contribution: It describes the adaptation requirements of the instrument to the study subjects, explores task load indices during the use of user interfaces in subjects with different abilities, indicates the heterogeneity of the population and presents usability requirements and interaction characteristics for users with ADHD that allows to realize a design centered in the user.
\end{abstract}

Task Load, User Interface, Mobile

\begin{abstract}
Resumen
Objetivos. Medir la carga congnitiva de las interfaces de Usuario en aplicaciones móviles didácticas en niños con TDAH utilizando el instumento NASA-TLX. Explorar la viabilidad de uso del instrumento NASA-TLX para medir la carga cognitiva en usuarios con capacidades diferentes. Metodología. Estudio exploratorio de muestra cualitativa con aplicación directa de un instrumento NASA-TLX adaptado a usuarios con TDAH que utilizan una app móvil didáctica con grupo etáreo de 5 a 15 años en la población del CAM\#8 en Moctezuma, Sonora. El instrumento se aplica de forma indirecta, asistidos por la educadora para interpretar las resupuestas de los sujetos. Contribución. Describe los requerimientos de adaptación del instrumento a los sujetos de estudio, explora índices de carga cognitiva durante el uso de interfaces de usuario en sujetos con capacidades diferentes, Señala la heterogeneidad de la población y presenta requerimientos de usabilidad y características de interacción para usuarios con TDAH que permita realizar un diseño centrado en el usuario.
\end{abstract}

Carga Cógnitiva, Interfáz de Usuario, Móviles

Citation: PONCE-MENDOZA, Ulises, GARCÍA-GORROSTIETA, Jesus Miguel and MADRID-MONTEVERDE, José David. Task load in user interfaces on didactic mobile applications for users with ADHD. Journal of Computational Systems and ICTs. 2020. 6-17:1-6. 


\section{Introduction}

In the present project, a cognitive ergonomics study was carried out with the objective of describing the mental load in the use of an educational application (App) for Android, which has eight didactic activities where children with ADHD problems (disorder deficit hyperactivity disorder) can interact, acquire knowledge and reinforce their learning, through simple games and initial level lessons. This application developed at Universidad de la Sierra, has the purpose of reinforcing the activities carried out within the CAME study centers, in particular the one located in Moctezuma, Sonora.

For the evaluation of this study, the NASA TLX Method (Hart \& Staveland, 1988) was used as a diagnostic tool to evaluate mental load factors during the performance of a task or manipulation of a system. This method was chosen because it includes a multidimensional assessment procedure that can be interpreted through a general index of said mental load.

Due to the characteristics that children present, we are in a situation in which work performance requires a high level of attention and generates a level of frustration on the part of the user (Arquer \& Nogareda, 2000);

\section{General objective}

Contribute to the development and learning process that is carried out in the Educational Programs of the Specialized Centers of Multiple Attention (CAME) through the software (App) with which children with different abilities, especially ADHD, can interact, acquire and reinforce your learning through games and activities in an ergonomic way.

\section{Specific goal}

Explore mental load indexes that allow designing user interfaces adapted to the cognitive abilities of users to decrease the mental load of use.

\section{Scope}

This study is mainly aimed at children with different abilities, specifically children with ADHD belonging to the age group of 5 to 15 years in CAM \# 8 of Moctezuma, Sonora.

\section{Methodology}

As it is an exploratory project, in this first iteration, it was agreed with the CAM Educators to develop a rapid intervention prototype that allows obtaining study data in a short time. The app requirements analysis was carried out through surveys of educators, who defined the type, degree of difficulty and content of the activities. For the development, the methodology for rapid prototyping of applications (Ponce Mendoza, Yánez Moreno, \& Soto Bernal, 2014) with MVC architecture, based on the structure of an Ionic Framework project, was used. The interface design was made following the indications of colors, distribution and iconography suggested by the CAME staff. Figure 1, 2 and 3.

The first study was carried out by applying the NASA TLX evaluation to six children from CAM \# 8, in order to identify the levels of effort, performance and frustration when using the application. The NASA TLX evaluation table used is known as the Raw Table, since the weight of the demanding activities is not established by the participants in the study, but by an expert in the area (Sebastián Cárdenas, 2016). In our case, the educator in charge of the group of children. Subsequently, the results were integrated into individual tables to generate the index that shows the correlation. Table 1.

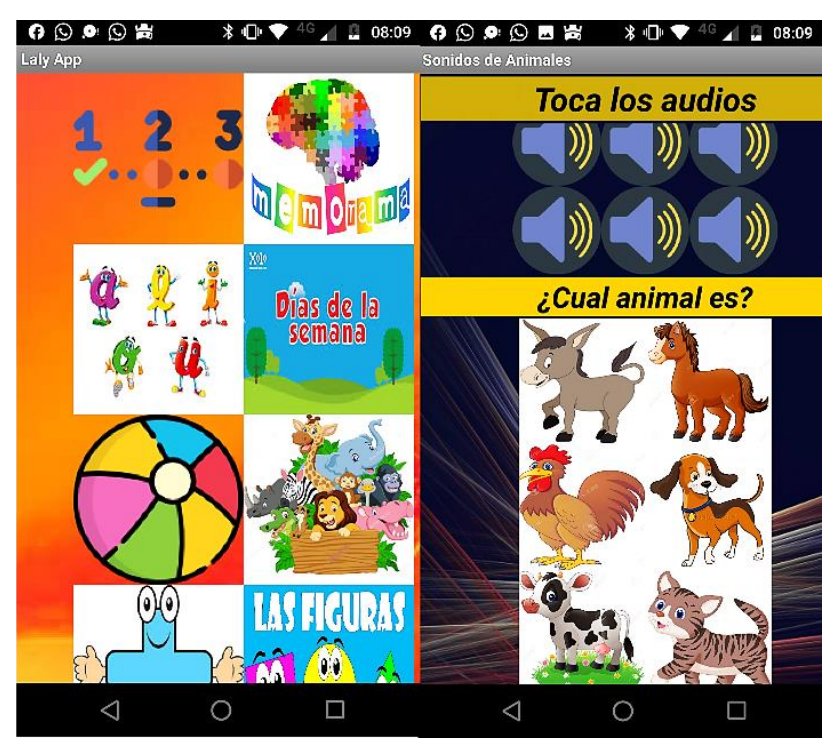

Figure 1 User Interface, first iteration Source: own elaboration 


\begin{tabular}{|l|r|r|l|l|}
\hline Variable & \multicolumn{2}{l|}{$\begin{array}{l}\text { (a) } \\
\text { Weight }\end{array}$} & $\begin{array}{l}\text { (b) } \\
\text { Degree }\end{array}$ & $\begin{array}{l}\text { (c) } \\
\text { Conversion } \\
\text { (b x 5) }\end{array}$ \\
$\begin{array}{l}\text { Weighted } \\
\text { Grade (c x } \\
\text { a) }\end{array}$ \\
\hline Mental Burden & 5 & 3 & 15 & 75 \\
\hline Physical Load & 1 & 0 & 0 & 0 \\
\hline Temporary Load & 1 & 1 & 5 & 5 \\
\hline Performance & 2 & 4 & 20 & 40 \\
\hline Effort & 3 & 3 & 15 & 45 \\
\hline Frustration & 3 & 0 & 0 & 0 \\
\hline TOTAL & 15 & 11 & 55 & 825 \\
\hline
\end{tabular}

Table 1 Mental Load Medium grade, subject "F" Source: own elaboration

The activities evaluated were "Identify animals", which consists of identifying visual of the image of an animal and is related in an auditory way with a representative sound. Likewise, a second activity (task) was evaluated with the association of vocal spelling and words that start with it.

The NASA-TLX methodology (Hart SG, 2006) incorporates a standardized evaluation instrument that analyzes six dimensions of activity and effort of the operators, namely: a) Mental Load, which defines the necessary amount of effort of perception and cognition is necessary In activities such as decision making, observation, memory, search and mental calculation, the aim is to identify if the task has been presented in the ranges from simple to complex, simple to demanding and precise or diffuse; b) Physical Load, establishes observations for the physical effort required such as pulling, moving, pushing, turning, among others, in our case we focus on the fine motor effort required by the subjects; c) Temporal load, refers to the mental effort to finish the activity in a certain time (temporal pressure) is measured in ranges of relaxed to fast and frenetic activities, in this study the temporal pressure was given when operating group activities with less devices that participants; d) Performance, establishes a comparison range from good to poor, for the perception that the subject has regarding the achievement of the task objectives by himself; e) Effort, defines how much cognitive and physical effort is necessary to complete the task or activity, it is comparable with activities performed by the subject previously, it is measured in ranges from high to low; and f) Frustration, defines in a low to high range the feelings and emotions related to insecurity, irritation, discouragement, frustration and stress perceived in the performance of the task.
To qualify the levels of effort, the instrument contemplates a 7-point scale ranging from no type of difficulty to very difficult. However, to adapt the test to the Likert scale, the scale was reduced from 1 to 5 , remaining as follows: 1.- Low; 2.- Medium-Low, 3.- Medium; 4.- Medium-High and 5.- High. For each of the questions measures an effort that increases and the higher the score, the greater the cognitive load. The only element with inverted graduation is the performance which, the lower it implies the greater the effort, therefore this item was graded in inverted form. This scale can be recognized in the tables in column (b) Degree.

On the other hand, column (a) Weight is a determination of the researcher and the CAM \# 8 specialists to point out the most preponderant factor in the total effort to operate the App by the subjects. For this, a Likert scale was also used, but with 5 levels, 5 being the most influential, up to 1 least influential.

The instrument indicates that it must be applied immediately after using the artifact (App) in order to collect the user's impressions regarding the dimensions used. In fact, this is the weakest part since the data collection was carried out with the intervention of a third party since our subjects have levels of deficiencies to null of spoken communication and therefore it is difficult to collect the information directly. The third who supported us in the process is the educator in charge of the group who observed the student in the use of the didactic mobile application and subsequently answered the NASA-TLX questionnaires.

Finally, the expected scale is a minimum of 450 points when interaction with the App is easy in all dimensions and 2250 when interaction with the App is not possible. The intermediate scale has been determined at 875 points.

\section{Sample size}

For the sample size, the total population of students from CAM \# 8 located in Moctezuma, Sonora was taken. Of which $21 \%$ are under 5 years of age which we will discard from the target population, therefore, only 6 of them will be taken into account for the study. 


\section{Results}

In an interview with the teacher in charge of the group of students under observation, the following qualitative results were obtained: a) Interest in the use of the application in the afternoon as a reward at home was positive for all students; b) The application activities positively reinforce the learning of the students in the CAME to favor the repetition of the activities seen in the classroom; and c) This application is compatible with children with intellectual disabilities to improve the recognition of sounds as with images and to identify figures, colors and letters.

The individual quantitative results of the NASA TLX application (Hart \& Staveland, 1988) yielded the following measurement, the measurements are an average of 3 shots each corresponding to the measured activities:

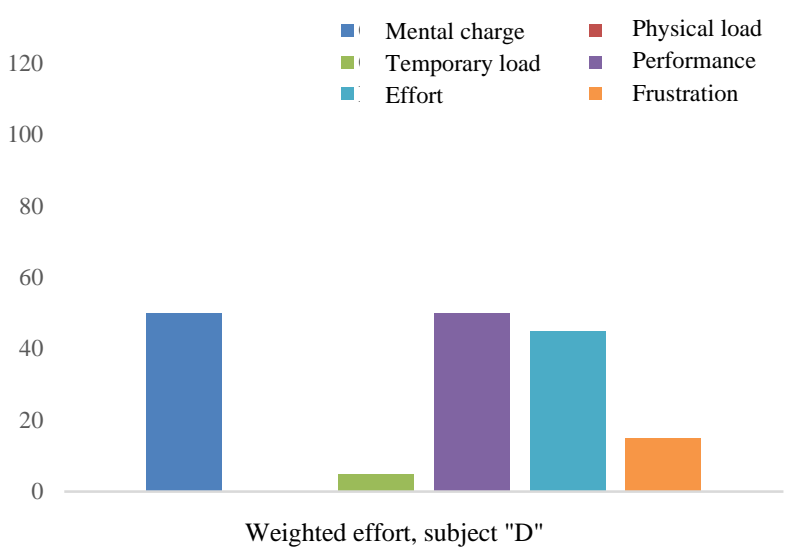

Graphic 1 Mental Load medium grade, subject "D" Source: own elaboration

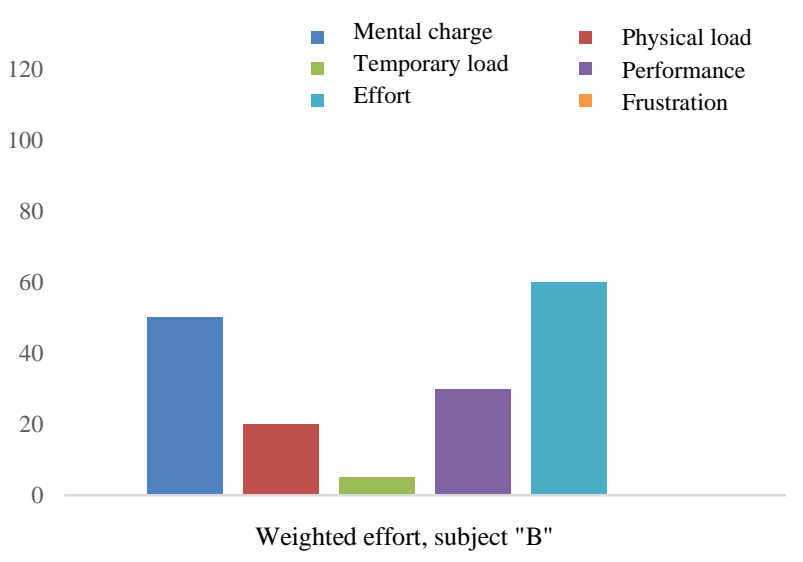

Graphic 2 Mental Load High grade, subject "B" Own elaboration

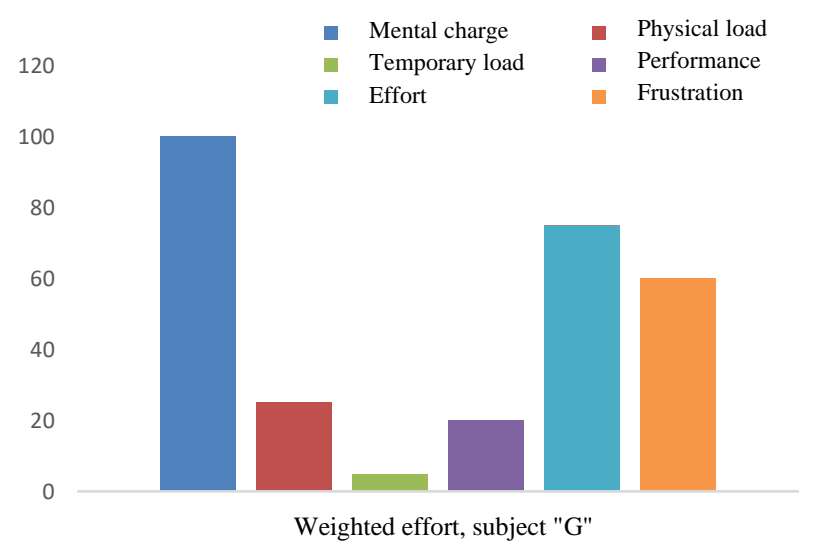

Graphic 3 Mental Load High grade, subject "G" Source: own elaboration

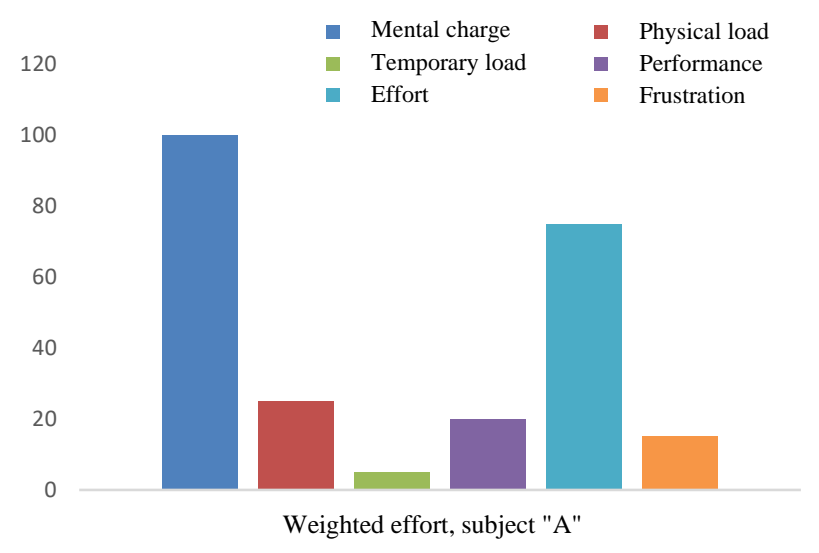

Graphic 4 Mental Load High grade, subject "A" Source: own elaboration

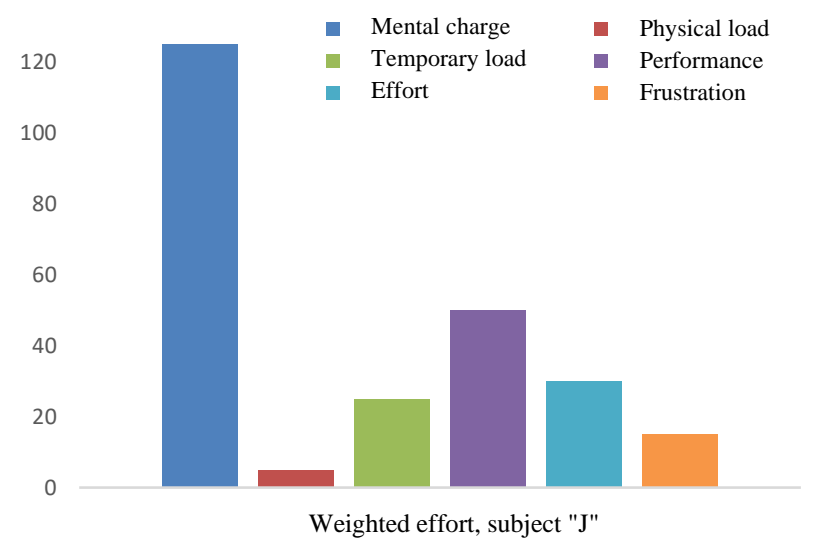

Graphic 5 Mental Load High grade, subject "J" Source: own elaboration

Among the interesting elements that we can describe is the level of frustration when using the App and that we can contrast it with the level of Mental Load, in which we observe that despite requiring a high mental load, the use of this type of application Children involved in the study are frustrated only when the app demands their full mental load. Likewise, we can see how decreasing the mental load decreases frustration on a non-linear level, but it has not yet been determined (Graphic 6). 


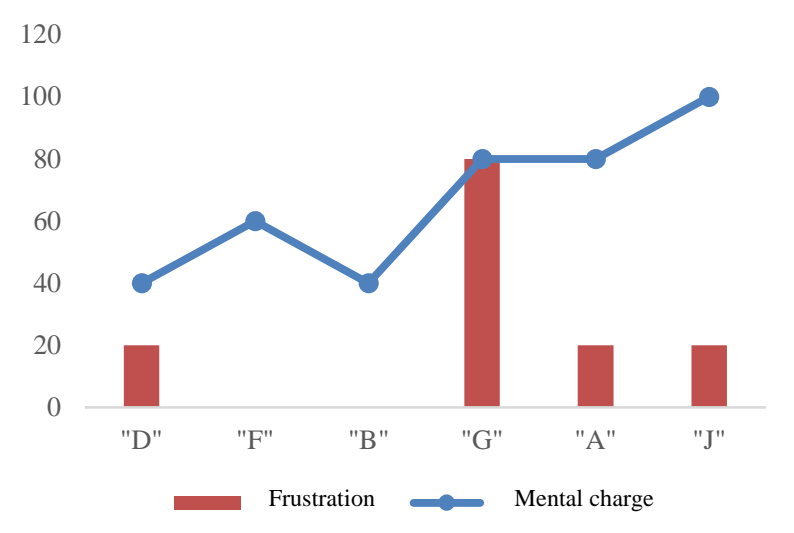

Graphic 6 Comparison between Mental Load and Frustration at the moment of using the App in percentage Source: own elaboration

In the same way, the physical usability, that is, the ease with which the input methods of the application allow interaction with the elements of the application, has a behavior in which it cannot be related as an element of frustration, that is, , the use of touch input does not seem to be related to the level of frustration as the cases are very diverse, noting that there are cases in which the levels of physical demand are high and those of frustration also up to cases in which the physical demand is very high and the level of frustration null, going through all the intermediate levels (Graphic 7).

Finally, with respect to the levels of cognitive load (Graphic 8) we can observe that despite the high motivation that the studied children show, the levels of cognitive load are High. This is confirmed since $100 \%$ of cases are above the Cognitive Load midpoint determined at 875 points. The lowest level detected was 900 points. However, there are good expectations regarding usability since more than $80 \%$ of the cases are in the third upper range of four possible, therefore, the cognitive load is demanding but not at levels of frustration. Situation that leaves the door open for improvements in the area of usability of the App.

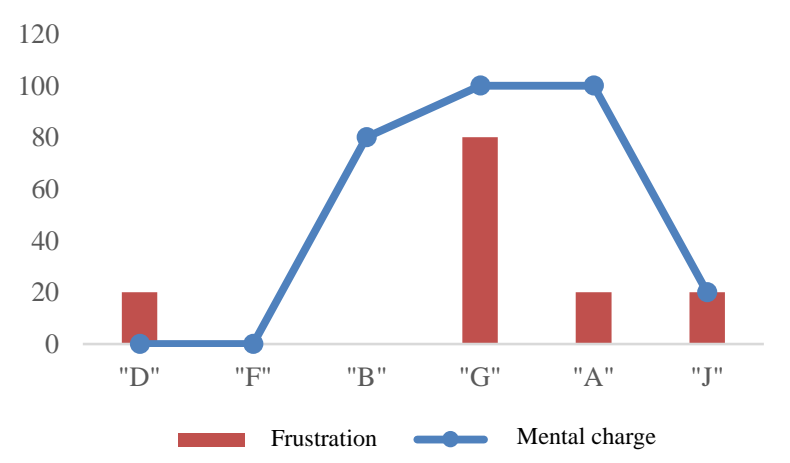

Graphic 7 Comparison of Physical Load and Frustration at the time of using the App in percentage

Source: own elaboration

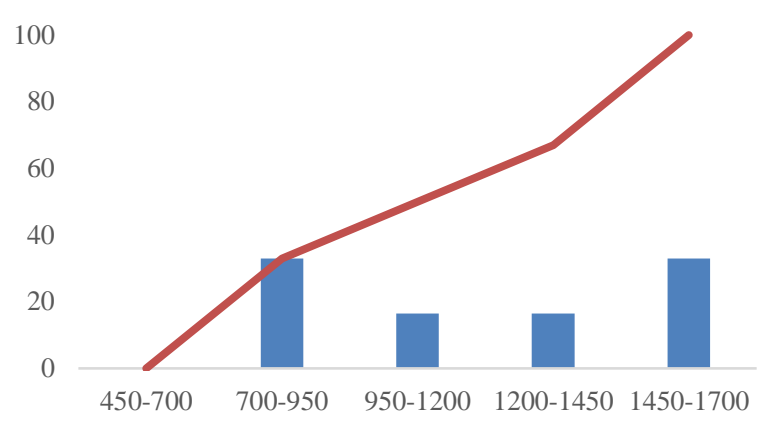

Graphic 8 Figure 4. Frequency and Accumulated Frequency in Cognitive Load Ranges

Source: own elaboration

\section{Conclusions}

I.- Due to the heterogeneous characteristics of the children evaluated and the small population reached to measure, it is not possible to carry out general statistics, therefore, it is proposed to take as reference the data from the Portal of the Secretary of Education and Culture of the State of Sonora (Planning, General Direction, 2019) in which we obtained a total population of 84 students from CAM \# 8 located in Moctezuma, Sonora. Of which $21 \%$ are children under 5 years of age, whom we will discard to take 66 children as the target population, for future studies.

II.- It is possible that there is a direct relationship between the condition presented by the child and the mental demand that can be tolerated in the use of the application.

III.- The application requires the addition of visual examples in each of the activities to reduce the initial frustration of not knowing how the selected activity works, which was one of the main items of low performance and high level of effort.

IV.- The NASA TLX tool (Sebastián Cárdenas, 2016) is suitable for measuring mental demand. It is necessary to increase the sample size to identify particularities between each disability or to rule out differences between them.

V.- In accordance with the recommendations issued by the educator and the results of the measurements, modifications will be made in the application to favor a low level of cognitive demand in its operation. 
VI.- The use of an application to reinforce learning in children with different abilities supports their retention capacity and facilitates teaching, as it is included as a tool based on cognitive ergonomics and provides an alternative that does not require learning new skills for its use.

\section{References}

Arquer, I., \& Nogareda, C. (2000). Estimación de la carga mental de trabajo: el método NASA TLX. Seguridad y Salud en el Trabajo, 2-6.

Fernandez, J., Marley, R., Noriega M, S., \& Ibarra M, G. (2010). Ergonomía Ocupacional, Diseño y Administración del Trabajo. Cd. Juárez: Universidad Autónoma de Ciudad Juárez.

Hart, S. G. (2006). NASA TLX Task Load Index. Recuperado el 24 de 01 de 2019, de Human Systems Integration Division: https://humansystems.arc.nasa.gov/groups/TLX /publications.php

Hart, S. G., \& Staveland, L. E. (1988). NASA TLX Task Load Index. Recuperado el 14 de 12 de 2018, de Human Systems Integration Division:https://humansystems.arc.nasa.gov/gro ups/TLX/publications.php

Planeación, Dirección General. (16 de 10 de 2019). Secretaría de Educación y Cultura del Estado de Sonora. Obtenido de Buscador de Escuelas en Línea 2019: $\mathrm{http} / / /$ planeacion.sec.gob.mx/upeo/ccts/

Ponce Mendoza, U., Yánez Moreno, V., \& Soto Bernal, R. A. (2014). Propuesta Metodológica para Desarrollo de Aplicaciones Móviles para. Congreso Internacional de Investigación Academia Journals 2014, Villahermosa, Tabasco, 1429-1434.

Sebastián Cárdenas, M. L. (2016). Apuntes de Ergonomía, Reflexiones para la Práctica de las Evaluaciones Ergonómicas y Psicosociales. Sevilla: Fundación para la Formación y la Práctica de la Psicología. 